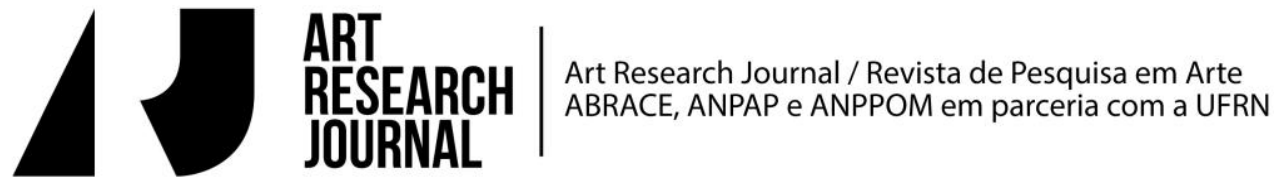

\section{Pesquisa, Experimentação e Criação em Teatro no Século XX}

Marco De Marinis

Tradução do francês: Paulo Pinheiro (UNIRIO)

\section{Introdução}

Pode-se defender a ideia de que os artistas sempre experimentaram e fizeram pesquisa em seu trabalho de criação. Com exceção dos casos, aliás muito frequentes sobretudo nos séculos passados, da criação de gênero, totalmente limitada pelas convenções, regras, princípios pré-fixados, pré-codificados.

No fim do século XIX, com a irrupção das vanguardas históricas, aconteceu algo novo em relação ao passado: a crise que afetou as velhas convenções, as velhas regras, as velhas formas expressivas, os gêneros codificados transformou artistas em experimentadores e, em certos casos, em pesquisadores, algumas vezes de modo muito próximo ao sentido científico do termo. Sobretudo quando era necessário passar da fase destrutiva (pars destruens) à fase reconstrutiva (pars construens).

Ainda que seja sempre difícil distinguir claramente as duas coisas, podemos pensar a hipótese seguinte: em arte (como em outros lugares) pesquisar implica sempre em experimentar, ainda que o inverso não seja sempre verdadeiro. Podemos imaginar artistas que experimentam sem propriamente fazerem pesquisa, de modo a defini-los como pesquisadores, no sentido próprio da palavra (mas é claro que será preciso especificar também esse "sentido próprio da palavra").

Pode-se estabelecer a seguinte distinção entre experimentadores e pesquisadores, pelo menos em relação ao domínio teatral: (1) os artistas experimentadores testam na sua prática novos meios de expressão, ou novos meios de usar antigos meios expressivos; (2) os artistas pesquisadores, 
experimentando através de um longo trabalho simultaneamente prático e teórico, tentam buscar e fixar novos princípios, regras novas, com vistas eventualmente a codificar novas formas artísticas, novas linguagens e produzir, em todo caso, conhecimentos inéditos no seu próprio domínio artístico.

Provavelmente, como já havia antecipado, essa distinção é muito abstrata e muito teórica. Na realidade histórica do teatro, constata-se que essas duas figuras, o experimentador e o pesquisador, estão frequentemente misturadas. No entanto, pode-se afirmar com alguma certeza, por exemplo, que Jarry ou Artaud foram mais experimentadores que pesquisadores; como mais tarde o foram Kantor, Carmelo Bene, Brook, Julian Beck e Judith Malina do Living Theatre, Mnouchkine, Robert Wilson.

No entanto, uma coisa me parece certa: o teatro do século $X X$, na forma específica do "teatro de encenação" (Théâtre de la mise en scène, Teatro di reggia, Direction Theatre) foi inventado por artista-teóricos (como eles foram chamados), verdadeiros artistas-experimentadores-pesquisadores: Appia, Fuchs, Craig, Stanislavski, Meyerhold, Copeau, Osterwa, Decroux, para citar apenas os mais importantes.

Um primeiro dado comum a todos esses artistas-pesquisadores é a desproporção entre pesquisa e resultados artísticos (espetáculos, etc.) que suas obras apresentam. Quase sempre, nesses casos, os resultados artísticos são reduzidos em relação à extensão, intensidade e profundidade da pesquisa e de seus resultados culturais, estéticos, às vezes até científicos. Nos casos de Appia e Craig, em relação aos quais falou-se impropriamente de afasia, uma situação muito mais difusa é dilatada de maneira macroscópica. Tanto no caso de Appia como no de Craig, o trabalho de experimentação e de pesquisa se desenvolve fundamentalmente longe do tablado, da cena material, no nível da página escrita e da imagem desenhada ou gravada, com a ajuda, no caso do encenador inglês, do model stage, essa maquete, esse teatro em miniatura que representou, durante muitos anos, o verdadeiro lugar de tão minúsculo laboratório, para antecipar um termo que introduzirei em seguida.

Aliás, esta desproporção entre pesquisa e resultados artísticos é típica de momentos de ruptura e de refundação de uma arte. Para Appia e Craig tratavase da passagem de um mundo da produção teatral à moda antiga, baseada no ator e no autor, a um modo de produção baseada no encenador e em princípios 
novos, ainda por serem descobertos, da encenação. No caso de Laban e Dalcroze, a ruptura foi total com a dança acadêmica: uma tabula rasa que impôs a necessidade de uma refundação a ser descoberta por experimentação, por ensaio, por pesquisa (depois das ações pioneiras no campo da improvisação de Isadora Duncan, Ruth Saint-Denis, Loie Fuller).

\section{Os teatros laboratórios no século $X X$}

O lugar privilegiado da pesquisa teatral no século $X X$ foi o Laboratório, muitas vezes chamado também de Studio ou Atelier, sobretudo na primeira metade do século: um lugar no qual encenadores-pedagogos, a começar, claro, por Stanislavski, se concediam o luxo de um tempo que, em geral, não era permitido à direção ou à produção de espetáculos. Transformaram assim a escola, de momento de transmissão de um saber e de um saber-fazer já conhecidos e codificados, num espaço-tempo consagrado à experimentação e à pesquisa de um saber e de um saber-fazer novos (princípios, regras, técnicas, etc.), capazes de modificar também os próprios pesquisadores.

Ao mesmo tempo, ao fundar os teatros-laboratório ou os estúdios, os encenadores modificaram a ideia mesma de teatro e de trabalho teatral: não se identificam mais completamente com o espetáculo ou com o trabalho de criação, porque nos estúdios ou nos teatros-laboratórios, em relação à criação, o experimentar e o pesquisar ganham a dianteira.

Evidentemente existem muitas diferenças entre os estúdios e ateliês da primeira metade do século XX e os Teatros-Laboratórios da segunda metade. A mais importante diferença consiste no fato de que os estúdios e os ateliês nascem no interior de uma realidade teatral preexistente e bem mais ampla, da qual se distanciam, como num momento de reequilíbrio. Se o teatro está totalmente voltado para a criação e a produção de espetáculos, o estúdio vira as costas à performance, para se consagrar a um trabalho que não está finalizado nem relacionado ao espetáculo (cujo caso exemplar é o do Primeiro Estúdio de Stanislavski, criado em 1911, ao lado do teatro de Arte, o qual dirigia junto com, mas totalmente separado de Nemirovic-Danchenko). Podemos também mencionar Meyerhold ou Copeau, enquanto que Dullin, com seu atelier representa talvez uma exceção que antecipa os teatros-laboratórios que se sucederam. 
Ao contrário, os teatros-laboratório, a começar pelos primeiros e mais famosos, como os de Grotowski e Barba, fundados na primeira metade dos anos 1960, reuniram sob esse nome e numa só realidade as entidades até então separadas: o teatro com sua exigência de criação e de produção de espetáculos com o laboratório, que dá as costas ao espetáculos. É nisso que consiste sua novidade e a força de sua provocação, que fizeram do teatro-laboratório um "oximoro encarnado" ou uma "contradição viva", como diz Mirella Schino na Introdução de seu belo livro Alchimisti della scena: teatri laboratori del Novecento europeo (2009, p. v).

Não é fácil definir de maneira unívoca o que seja um teatro-laboratório, ou distinguir entre teatro laboratório, laborialidade, dimensão laboratorial; ou, ainda, de precisar as afinidades e diferenças em relação ao laboratório científico no sentido estrito do termo.

O livro de Mirella Schino nos ajuda, em todo caso, a dar os primeiros passos nessa direção, sobretudo porque se propõe a ser o arremate de uma longa discussão coletiva que durante anos afetou um grupo de pesquisadores ligados a Eugênio Barba e à ISTA, International School of Theatre Anthropology.

Para adiantar mais o pensamento sobre o assunto, é preferível exemplificar. Por isso, a segunda parte de minha contribuição será dedicada à análise de três casos diferentes de pesquisa-experimentação-criação no século $X X$, portanto três exemplos diferentes de laboratório teatral: Decroux, Grotowski e Barba. O exame desses três exemplos permitirá também algumas considerações sobre as noções de progresso, desenvolvimento, descoberta e demonstração na pesquisa em arte e em particular no teatro.

\section{Etienne Decroux}

Primeiro é preciso dizer que no caso de Decroux, seu longo trabalho de pesquisa e de experimentação leva à invenção de uma nova arte teatral, a mímica corporal, com a definição de novos princípios e regras inéditas: uma gramática corporal inteira, verdadeira gramática do corpo e do movimento expressivo. Isso significa efetivamente que a pesquisa de Decroux ultrapassou de longe a finalidade específica da criação da mímica corporal dramática a que se destinou. É possível distinguir pelo menos três níveis interligados no interior de sua pesquisa artística e pedagógica: 
1) existe, antes de tudo, como acabo de dizer, o Decroux inventor da mímica corporal como novo gênero teatral, um gênero fundado na exclusão rígida de termos e em princípios fortemente codificados, caso reconhecidamente muito raro no ocidente;

2) depois há o Decroux pesquisador de uma arte teatral pura, essencial, fundada sobre o uso estético do corpo humano, mas sem exclusão rígida e sem obrigação de codificação/formalização estrita;

3) enfim, existe o terceiro Decroux: aquele que perseguiu durante mais de cinquenta anos uma das buscas mais rigorosas, profundas e sistemáticas que o teatro europeu jamais conheceu em relação aos fundamentos da arte do ator, quer dizer, sobre a ação física da cena, suas técnicas, seus princípios, sua dramaturgia.

É sobretudo esse terceiro nível que nos permite considerar Decroux um verdadeiro pesquisador no domínio do teatro contemporâneo e também considerar o seu longo trabalho artístico-pedagógico-técnico-teórico (sem clara distinção entre esses aspectos) um verdadeiro teatro-laboratório.

Evidentemente aqui não é o lugar de explicar detalhadamente em que consistem as aquisições técnicas e artísticas da pesquisa de Decroux (sobre o que já publiquei extensivamente em várias línguas). Dessa vez interessa aprofundar algumas características que permitam valorizar em seu trabalho o caráter de pesquisa.

A propósito do caráter exasperadamente sistemático de sua pesquisa, deve-se ressaltar que Decroux passou mais de meio século a experimentar e a denominar gestos e gestos de mãos, de braços e de pernas, movimentos e atitudes corporais, fixando assim o léxico e a gramática de um corpo "outro", de forma incrivelmente minuciosa, desde o início. E ainda criou centenas e centenas de exercícios, batizados com nomes bem concretos e ao mesmo tempo fantasiosos, como "antenas de escargot", "asas de águia", "a bela curva", etc.

Evidentemente estamos diante de uma pesquisa técnica feroz, exasperada, quase sem sentido ao olhar, excessiva para a maioria das pessoas, que demonstra - tanto no caso do mímico francês como no caso de outros mestres uma dupla potencialidade oposta: de um lado a via de acesso obrigatória para se chegar ao cerne dos problemas da arte cênica; por outro lado, e simultaneamente, a 
via privilegiada que o teatro do século $X X$ seguiu para se transcender, para ir além de si mesmo, além do espetáculo, e também além da arte, às vezes por meio de uma interrogação radical sobre o valor e o sentido da arte.

Uma segunda característica de seu desempenho de pesquisador rigoroso consiste no fato de ter ido sempre contra a corrente, contra o espírito do tempo, contra as modas e o sucesso: "É preciso sempre estar a favor de quem é contra, e contra quem está a favor", dizia ele, "Se você faz sucesso, desconfia! É preciso voltar a estudar" (Marc, 2003, p. 452).

Em seguida, é preciso lembrar a prioridade pedagógica de seu trajeto como artista-pesquisador. Mais ainda, no seu caso, pode-se e deve-se falar de uma verdadeira vocação pedagógica: "Como não termos desejo de converter as pessoas?", se perguntou uma vez, durante uma conferência.

Essa vocação pedagógica por si mesma impregna os diferentes níveis e formas de sua criação artística, atingindo as elaborações teórico-experimentais que concernem a arte do corpo e suas leis ou princípios. Dito de outro modo, é sua pesquisa científica e criativa sobre a mímica que se configura como intrinsecamente pedagógica (mas, também o contrário pode ser verdadeiro).

Outra característica suplementar: no desempenho de Decroux é muito difícil, quase impossível, distinguir entre o teatro e a vida, o ensino e a vida, a pesquisa artística e a vida, a partir do fato de que - em particular depois de 1962 - o local de existência tanto pública quanto privada de Decroux passou a ser único: a casa de Boulogne-Billancourt em Paris, onde ele viveu os últimos trinta anos de sua vida, de lá saindo muito raramente. Era lá que vivia, trabalhava, ensinava, experimentava e criava.

No entanto, para além da íntima fusão de todos os aspectos e níveis de que falamos, à exigência de pesquisa contínua e de experimentação ininterrupta aliou-se sempre, de forma prioritária, o respeito à necessidade de construir obras acabadas e produtos terminados. Entre outros princípios, a prioridade é dos segundos termos: "Teatro experimental? Se eles querem fazer uma verdadeira experiência, devem se livrar do público". Essa prioridade nunca foi realmente discutida, mesmo na época de ouro dos anos 1945-1962. Ela realmente nunca se traduziu em recusa da criação artística, mas de uma concepção da criação como 
meio de experimentação e de verificação; em resumo, como estudo, ensaio, demonstração.

\section{Jerzy Grotowski}

A primeira coisa a observar, também no caso de Grotowski, é sua atitude de pesquisador, que caracteriza todo o seu percurso no teatro e para além dele. E é necessário, logo em seguida, acrescentar que sua escolha pelo teatro na juventude estava ligada a motivações absolutamente não artísticas, mas intelectuais e existenciais. Tal como revelou a Marianne Ahrne em 1992:

Jamais procurei o teatro, na verdade estive sempre à procura de outra coisa. Na juventude, perguntava-me qual era a profissão possível para descobrir o outro e a si próprio. [...] No fundo, foi esse interesse pelo ser humano, nos outros e em mim mesmo, que me levou ao teatro, mas isso poderia ter me conduzido à psiquiatria ou aos estudo da yoga (De Marinis, 2011, p. 191).

Dito isso, fica evidente que sua escolha por denominar desde cedo o seu teatro de "teatro-laboratório", referindo-se aos lugares designados pela pesquisa científica, não foi, de modo algum, casual. Os especialistas poloneses nos explicaram as inúmeras razões que estão por trás dessa escolha, começando pelas razões práticas (libertar-se da obrigação de uma produção constante de certo número de espetáculos por ano, etc.). Sem dúvida, para a determinação de sua escolha concorreram, também, seu interesse pelas ciências como a física (seu irmão mais velho era físico nuclear, e o Instituto Bohr, em Copenhague, o fascinava e era para ele um verdadeiro modelo), o fato de que para ele "era muito mais fácil se comunicar com os representantes das ciências do que com os representantes das disciplinas humanistas"; enfim, last but not least, suas predisposições pessoais, o que Osinski chama de "seu background laboratorial" (Schino, 2009, p. 141).

Em todo caso, na metade dos anos 1960, já era evidente que o TeatroLaboratorial de Wroclaw havia se tornado um verdadeiro núcleo de pesquisa. Confirmando essa tendência, a consagração viria de Peter Brook, com o seu famoso artigo de 1967, que seria publicado no ano seguinte como prefácio do livro de Grotowski, Vers un théâtre pauvre (Em busca de um teatro pobre) (Brook, 1971, p. 9). 
Mas é necessário ler diretamente esse livro se queremos compreender melhor as ideias que Grotowski tinha, naquela ocasião, sobre as relações entre o teatro e as ciências, sobre as afinidades e as diferenças entre pesquisa teatral e científica.

No capítulo "Pesquisas sobre o método", baseado em artigo publicado em 1967, Grotowski começa descrevendo o Instituto Bohr de Copenhague, depois observa:

O Instituto Bohr me fascinou, por muito tempo, como o modelo ilustrativo de certo tipo de atividade. Claro, o teatro não é uma disciplina científica, menos ainda a arte do ator sobre a qual concentro minha atenção (Grotowski, 1971, p. 95).

Contudo, segundo ele, é necessário individuar "as condições essenciais da arte e do ator" e torná-las "objeto de pesquisas metódicas" (Grotowski, 1971, p. 96).

Após essa fase, Grotowski falará cada vez menos de métodos e de leis do ato criativo, mas continuará se ocupando, como pesquisador, do ator (ou melhor, do performer) e das técnicas que se encontram na base do que, doravante, ele chamará de performing arts em vez de teatro. E ainda que o seu feeling com os homens de ciência permaneça inalterado até o fim (seu irmão assim o testemunhou após sua morte), seu trabalho de pesquisador se aproxima, de preferência, seja pelo método (o trabalho de campo) seja pelo objeto, da antropologia cultural. Mas Kolandiewiski tem, no entanto, razão quando supõe que, na medida em que progride, a pesquisa de Grotowski se assemelha cada vez mais a de um alquimista e não a de um homem de ciências modernas (citado por Schino, 2009, p. 153-154).

Em seguida, gostaria de me referir às pesquisas elaboradas por Grotowski sobre o ritual e as suas relações com o teatro, pesquisas teórico-práticas, artísticocientíficas, que o conduzem, do início ao fim e de modo descontínuo, para além das transformações que interferem em sua conduta teatral e pós-teatral (De Marinis, 2011, p. 139-166).

Ocupando-se com o ritual, de diversos modos, em toda a sua vida, Grotowski nos legou uma contribuição fundamental em dois níveis:

- enquanto artista-artesão, revelou que é possível seguir uma via de trabalho focada em si-próprio (e na relação com o outro a partir de si, na medida em que o outro faz parte de si) definível em termos de "ritual laico", ou seja, não baseado na "fé", mas no "ato"; 
- enquanto cientista-antropólogo, na medida em trouxe contribuição considerável à fundação de um campo de pesquisa e de uma metodologia de investigação interdisciplinar sobre as performing arts, isso ele fez por meio de contribuições stricto sensu científicas (especialmente a partir da biologia e da neurobiologia) aproximadas às perspectivas teatrais, fundadas no antropológico e orientadas de modo pragmático. Podemos dar a esse campo e a essa metodologia de investigação interdisciplinar o nome que o Collège de France elegeu para acolhêlas (o de "antropologia teatral") ou talvez outro nome, isso não é importante. 0 que conta é sublinhar o ethos stricto sensu científico, ou seja, no sentido de ciências "duras" (exatas), naturalistas, que sempre caracterizou o seu desenvolvimento e que se encontra, igualmente, nas diversas denominações com as quais designou, com o passar dos anos, seus projetos.

Voltando às relações entre rito e teatro, é necessário dizer, a princípio, que Grotowski nunca rejeitou a ideia da origem ritual do teatro, ideia professada abertamente nos anos 1960; mas, no decorrer do tempo, sua visão sobre essa questão tornou-se muito mais complexa, difusa e também, muitas vezes, até mesmo contraditória. Como demonstra o importante curso dado em Roma (Grotowski, 1982), em que a relação entre o teatro e o rito e a análise do ritual constituem um dos leitmotive.

Vamos percorrer a parte publicada desse curso para deixar emergir as elaborações teóricas mais interessantes quanto ao nosso tema. Como já anunciei, a ideia de uma filiação entre rito e teatro nunca é totalmente abandonada, mas adquire contornos cada vez menos genealógico-evolucionistas para dar lugar a uma oposição estrutural, para dar vez, enfim, a uma outra polaridade sobre a qual Grotowski sustenta sua visão, que ele restringe, pouco a pouco, ao campo das performing arts e das práticas performativas. Assim, o esquema "do rito ao teatro" torna-se "rito vs teatro" (aqui com o termo teatro tomado em seu sentido mais restritivo de espetáculo, de representação).

No esquema sincrônico-estrutural "ritual vs teatro" os dois termos tornam-se as extremidades de um continuum de possibilidades intermediárias e, ao mesmo tempo, as dimensões opostas constitutivas de todo fenômeno de performing arts, ainda que em proporções diferentes num caso ou noutro; um par antagonista, uma polaridade, justamente, que se superpõe ao par organicidade/artificialidade sem, porém, the corresponder completamente. A 
utilização de um paradigma sincrônico no lugar de um paradigma diacrônico permite a Grotowski ler um (o teatro) nos termos do outro (o ritual) e viceversa, ou seja, permite encontrar algo de ritual no teatro e algo do teatro no ritual (como se fosse o caso, justamente, de dimensões constitutivas ou de níveis de organização).

Uma das mais importantes contribuições em conhecimentos sobre a natureza e o funcionamento dos rituais que Grotowski nos fornece nas lições romanas consiste, precisamente, em resolver sua diferença face aos clichês e estereótipos que, ainda hoje, e mesmo muitas vezes no terreno científico, condicionam o modo ocidental de ver o rito, o transe e a possessão.

Ele repetiu, infatigavelmente, que o ritual (autêntico, vivo) não constitui uma desagregação selvagem e uma perda do controle, mas, pelo contrário, ele se funda na precisão de uma estrutura conhecida durante muitos anos de treinamento, desde a infância. Em resumo, nos rituais vivos encontramos organicidade, mas há também, e apesar de tudo, organização, e é a primeira que depende da segunda mesmo que isso possa nos parecer paradoxal, a nós, ocidentais.

O que segundo os clichês ocidentais constitui a regra (a saber, que a possessão seria inconsciente, sem controle e constitutiva de uma desagregação selvagem) se verifica, pelo contrário, se bem examinado, ser apenas uma exceção, via de regra socialmente desqualificada nas culturas tradicionais: é o caso no Haiti, onde existe, justamente, um termo, bossal, para designar com desprezo a possessão selvagem. Grotowski insiste nesse ponto: "Para eles [os Ocidentais], a possessão e a consciência se opõem, possessão consciente é um oximoro, nada há de mais superficial" (Vacis, 2002, p. 92-93). ${ }^{1}$

De fato, segundo a análise do mestre polonês, a possessão selvagem e o comportamento histérico no ritual não indicam apenas falta de preparação e improvisação não profissional, como no caso do bossal haitiano, mas, com frequência, - e isso é bem mais interessante - são tomados como sintomas de uma desagregação-degradação do próprio ritual, índice de que se torna outra coisa, de que está indo (deslizando, declinando) na direção do teatro, compreendido aqui como representação-ficção para o outro, para o público.

\footnotetext{
${ }^{1}$ Ver também Grotowski 1982, p. 2-8; sobre vodu haitiano ver p. 108.
} 
Nesse intuito, Grotowski distingue o "transe são (saudável)" do "transe insano" (Grotowski, 1982, p. 9-11; 70-), e os rituais vivos dos rituais falsos:

É bem fácil se enganar e tomar um falso ritual por algo de verdadeiro, porque há muitos falsos rituais. Nos falsos rituais, se assiste, habitualmente, a um fenômeno que poderíamos qualificar de histérico (Vacis, 2002, p. 95).

Esse fenômeno histérico, que induz a diferentes tipos de comportamentos incoerentes (movimentos descontínuos, interrompidos, gestos com as mãos e os pés dobrados como garras etc.) (Vacis, 2002, p. 96) ${ }^{2}$ e à baixa da vigilância-consciência-atençãoconcentração (como, precisamente, no transe insano, enquanto que no transe são se constata, pelo contrário, uma elevação do nível de atenção-concentração) (Grotowski, 1982, p. 9-11) estão associados, segundo Grotowski, à presença do espectador e ao fato de se agir para eles (Vacis, 2002, p. 96; 229-).

As distinções entre transes sãos e insanos, e rituais verdadeiros e falsos, permitem a Grotowski enriquecer a polaridade ritual/teatro de nuanças e de possibilidades intermediárias.

Em um primeiro momento, a partir de filmes etnográficos doravante clássicos, ele distingue três níveis:

- "o ritual em sua plenitude viva", documentado num filme de Maya Deren sobre o vodu (ou melhor, em certas cenas sobre o transe e a possessão) $i^{3}$

- "o ritual em seu estado de formalismo", marcado pela "dominação do aspecto simbólico sobre o aspecto da vida" (no qual se descobre um testemunho, segundo ele, no filme de Jean Rouch, Yenendi ou les hommes qui font la pluie, de 1951 (Grotowski, 1982, p. 114-116);

- "o início do teatro e o fim do ritual", sustentado pelo célebre Les maîtres fous (1952), também de Rouch (Grotowski, 1982, p. 125-126).

Na sequência das lições, a análise de outros documentos audiovisuais o leva a enriquecer ainda mais sua tipologia e, portanto, as nuanças intermediárias entre ritual e teatro:

\footnotetext{
2 "Le vrai rituel produit des ondes de mouvement, le faux produit des points de mouvement".

3 O filme documentário, Divine Horsemen. The Living Gods of Haiti, facilmente encontrável na internet foi filmado entre 1947 e 1951.
} 
- por exemplo, no filme de Margaret Mead, Trance and Dance in Bali (1939), ele observa "a coabitação do ritual e do teatro" (Grotowski, 1982, p. 169; 163-);

- e há, enfim, "o ritual representado, imitado", o que "acontece, com frequência, quando o ritual está prestes a fracassar", e onde o "teatro de vanguarda ou de pesquisa" também, com frequência, se ilude.

\section{Eugenio Barba}

No caso de Barba, também estamos diante de um verdadeiro pesquisador (desde o início) com - em particular - uma inclinação constante para a "ciência do teatro", aquela que está em busca de princípios e regularidades interculturais e transculturais para a "frágil arte do teatro" (Schino, 2009, p. 33). Essa sua inclinação também se nutre de um interesse constante pelas ciências duras, como a física, a biologia, a psicologia experimental, etc. Seu diálogo com os homens de ciência lembra os de Stanislavski ou os de Meyerhold no início do século XX (para não falar, evidentemente, do seu mestre, Grotowski).

Durante anos Barba devorou, por uma lado, uma montanha de livros científicos; por outro, desenvolveu uma longa pesquisa de campo, na condição de um autêntico antropólogo, sobre vários teatros orientais, em particular os indianos, balineses e japoneses. Seu estudo sobre o teatro-dança Kathakali, em 1963, foi o primeiro no Ocidente.

$\mathrm{Na}$ origem do ISTA (International School of Theatre Anthropology) e da Antropologia Teatral, que nascem juntas no fim dos anos 1970 - graças a ele apresentam-se dois elementos: o interesse pelas ciências e o trabalho de campo sobre os teatros orientais, sem excluir, claro, a pesquisa prática, técnica e artística trabalhadas, conjuntamente, desde 1964 com o seu grupo Odin Teatret.

Desde 1980, o ISTA torna-se, para Barba, o instrumento - o espaço-tempo onde satisfazer suas pulsões de pesquisador e experimentar em grau, a uma só vez, teórico e prático - para investigar as possibilidades de uma ciência do teatro.

De fato, pode-se pensar o ISTA como um grande laboratório teatral ou como um grande teatro-laboratório intermitente. Como descreve Mirella Schino, "trata-se de um lugar pensado para a pesquisa sobre o ator" (Schino, 2009, p. 12), isso porque reunia, estimulando o ator a trabalhar em conjunto, praticantes e teóricos, homens de cena e homens de livros, de um lado e de outro, ocidentais e não ocidentais, asiáticos sobretudo. 
De agora em diante, gostaria de me concentrar na discussão sobre a Antropologia Teatral como disciplina científica ou mesmo como ciência, ciência do teatro (De Marinis, 2011, p. 35-97).

O que concluir, ao menos provisoriamente, com relação à questão da metodologia de estudo da Antropologia Teatral? Penso que não se pode considerar cientificamente impecável uma comparação descontextualizada, que põe em contato procedimentos e terminologias teatrais distintas e distantes da pesquisa de seus princípios transculturais, que dizem respeito a todos os atores "enquanto tais". Então, desse ponto de vista, não se pode deixar de estar de acordo com o fato de que

...por em evidência a morfologia elementar e oculta que compartilham os diversos atores não significa confundi-los com uma ideia única e universal de teatro (Barba 1993, p. 216-217).

Contudo, uma vez estabelecida a legitimidade de comparar, descontextualizando e recontextualizando, fica ainda a necessidade de verificar a exatidão dos modos pelos quais Barba efetua essa comparação. Quanto a isso, continuo a ter dúvidas, mesmo após a leitura de Le canoë de papier ( $A$ canoa de papel) e após ter frequentado várias sessões do ISTA. A esse respeito, os riscos que percebo podem ser resumidos, em sua grande maioria, nessa "homogeneização das fontes" às quais se refere o próprio Barba, seguindo a terminologia dos historiadores, subestimando, contudo, as suas implicações.

Todos aqueles que, por razões profissionais, têm o que fazer com os textos e com a necessidade de os citar, interpretar e construir, graças a eles, um outro texto ou, para ser mais exato, um discurso argumentado, uma hipótese histórica, crítica ou científica, no sentido estrito do termo, conhecem bem os riscos da homogeneização das fontes. E sabem muito bem que ela é, em certa medida, inevitável. Claro, esses riscos aumentam sensivelmente se os textos e os termos que utilizamos pertencem a línguas afastadas de nossas culturas, como no caso, por exemplo, das línguas asiáticas.

Ora, uma pesquisa que, como a da Antropologia Teatral, faz parte (é o próprio Barba que assim o diz com todas as letras) de um árduo e difícil trabalho de comparações lexicais (por exemplo: qual palavra corresponde na Índia, em Bali, na China ou no Japão a nossa palavra "energia"?) foi e ainda está muito exposta 
aos riscos dos equívocos ou da manipulação mais ou menos consciente dos enunciados e dos termos.

Tanto que, no caso de um pesquisador como Barba e de uma disciplina como a Antropologia Teatral, que tem muito a ver com os textos e as palavras, mas também, e sobretudo, com os seres humanos em carne e osso, o risco é duplo: além do risco da manipulação lexical e textual (do misreading), há também o risco da manipulação dos atores, uma manipulação performativa, por assim dizer.

Há muito tempo analisando Barba em seu trabalho com os atores - além de estar sempre fascinado por sua capacidade de elaborar demonstrações extremamente interessantes, mesmo apaixonantes -, com seus corpos e suas vozes, com a maestria e a disponibilidade dos atores, pergunto-me, com frequência, se é correto falar, nesse caso, de uma situação efetiva de laboratório no sentido científico do termo, ou seja, de condições cientificamente corretas para a observação comparativa dos fenômenos que dizem respeito ao ator (fenômenos performáticos) e dos princípios transculturais que, segundo a Antropologia Teatral, estão na base dos trabalhos tidos como científicos.

Toda vez que me deparo com essa questão (ou seja, quase sempre, assim que desperto do fascínio), não chego a suplantar as dúvidas. Claro, não sou ingênuo a ponto de ignorar a inexistência na realidade de situação experimental pura, totalmente neutra, que não seja influenciada, pelo menos em pequena escala, e justamente por aquele que a construiu visando obter certos resultados (isso é tão válido para os laboratórios de física teórica quanto para as pesquisas sociológicas em moda na atualidade). E, portanto, pergunto-me se nas demonstrações organizadas por Barba no ISTA não ocorre nada além disso e, muitas vezes, só se alcance uma espécie de wishful thinking, teoria que se auto realiza, para dizer como os filósofos da ciência.

Em verdade, as demonstrações de trabalho de Barba no ISTA constituem ensaios teóricos fascinantes escritos com os corpos e as vozes dos atores e não com palavras: trata-se, literalmente, de performance texts. As dúvidas sobre a validade científica delas não apagam a viva capacidade de persuasão que eles possuem.

A parte final desta exposição sobre Barba, pesquisador da área da ciência do teatro, será dedicada à reflexão sobre a identidade problemática, incerta, da Antropologia Teatral. 
O que é a Antropologia Teatral? O que ela quer dizer? Seria uma ciência, uma pedagogia do ator ou, talvez, uma estética? E no caso de tender a uma ciência teatral (claro, levando em conta todos os limites inevitáveis dentro dos quais seria possível fazer ciência partindo de um objeto cultural tão complexo como o teatro), de qual modalidade de ciência seria o caso? Mais uma vez, cedamos a palavra, antes de tudo, a $A$ canoa de papel. ${ }^{4}$ No cap. II, "Definição", Barba explica, logo no início, que a Antropologia Teatral atua em um duplo registro - no analítico-científico e no técnico-prático - e que, em função de seus princípios pré-expressivos, pretende produzir efeitos nos dois registros simultaneamente (Barba 1993, p. 23-24).

Esta duplicidade, ou ambivalência, é confirmada no início do capítulo seguinte:

A Antropologia Teatral é um estudo sobre o ator e para o ator. É uma ciência pragmática que se torna útil quanto permite ao historiador do teatro tocar com os dedos o processo de criação e quando, nesse mesmo processo, faz crescer a liberdade do ator (Barba 1993, p. 29).

Mas é, sobretudo, no capítulo IV que Barba se esforça para abordar mais amiúde as dúvidas ou as incertezas relativas à identidade dessa "ciência" de dupla face, analítica e/ou pragmática. São questões às quais ele responde, habitualmente, com outras questões; sem, contudo, permitir que se confirme essa natureza dupla, andrógena, por assim dizer, da Antropologia Teatral e, portanto, dos seus princípios.

\section{A Antropologia Teatral tem caráter científico?}

[...] Seu fundamento se encontra na pesquisa empírica, na qual encontra seus princípios gerais. Ela se situa na dimensão prática e visa, portanto, a eficácia da ação cênica. Ela está circunscrita a um setor de pesquisa e forja os instrumentos teóricos necessários à sua própria exploração. Ela sinaliza suas leis pragmáticas. Logo, é uma ciência (Barba 1993, p. 65).

Um pouco mais adiante, para aqueles que "estimam que a Antropologia Teatral postula uma objetividade científica impossível" Barba responde:

Não: nosso ponto de vista é firmemente e explicitamente objetivo, embora parcial. Projetamos sobre o nosso campo de estudo os questionamentos e as inquietações que pertencem à prática e ao artesanato teatral. Servimo-nos da objetividade funcional própria aos artífices do teatro (Barba 1993, p. 75).

${ }^{4} \mathrm{O}$ autor usa a edição francesa da obra de Barba (Lectoure: Bouffonneries, n. 28-29, 1993). 
Mas, enfim, é possível considerar científica uma aproximação prático-teórico deliberadamente ambivalente, como a que ocorre na Antropologia Teatral proposta por Barba?

A resposta encontrada, por exemplo, por Taviani é afirmativa: quando procuramos fazer ciência com fenômenos artísticos, a ambiguidade não constitui um erro perdoável, mas, de algum modo, um limite constitutivo, insuperável (De Marinis, 2011, p. 87).

A consequência lógica inevitável é - ainda seguindo Taviani - a de que os princípios elaborados pela ciência da arte (portanto também os princípios da Antropologia Teatral enquanto ciência da arte) não poderão jamais constituir "leis" verdadeiras, mesmo que tenham a aparência de tais "leis": "Parecem "leis", mas são, de fato, antologias miniaturizadas de procedimentos recorrentes, de relatos históricos dos quais se abstrai um desenho (De Marinis, 2011, p. 87). Todavia, continua, não é totalmente incorreto nem inútil designá-los como "leis", porque, com frequência, é conveniente considerá-los como se assim o fossem. Mas a quem convém? Por mais estranho que possa parecer, não convém ao pesquisador, mas ao artista:

Sobre as "leis" artísticas ocorre o seguinte: aqueles que as utilizam para compor, convém tratá-las como "leis" físicas iniludíveis; enquanto que aqueles que as examinam para construir uma ciência da arte, convém tratá-las como sínteses de testemunhos operativos, repertório empírico sobre o qual se aplica a arte das comparações (De Marinis, 2011, p. 88).

Tudo isso pode parecer um paradoxo reluzente, mas se trata, pelo contrário, de puro bom senso. De fato, é evidente que o artista só pode aplicar uma regra quando a assume, pelo menos provisoriamente, como absoluta. Ao invés disso, para aquele que procura descobrir regras e leis artísticas é conveniente e útil desconfiar, pelo maior tempo possível, da validade absoluta dessas regras e leis artísticas, submetendo-as, continuamente, à prova da verificação empírica e ao exame histórico.

Mas por quanto tempo? Mesmo para uma ciência fraca (ou bem fraca), como seria possível não tomá-la como ciência da arte e, particularmente, dos teatros; mesmo em uma ciência que se oferece, com humildade, como "estudo empírico das comparações entre comportamentos teatrais" (ainda Taviani), não se pode deixar de questionar a amplitude de suas comparações (quantos comportamentos comparar e até onde estender o domínio das comparações). Para dizer de outro modo, ela não 
pode evitar a apresentação do problema relativo aos limites da verificação históricocomparativa e das decisões assumidas no que tange à validade das, assim ditas, "leis" (de fato, as tendências recorrentes, os princípios-que-retornam) postas em questão pela comparação.

Em resumo, admite-se, de novo, o confronto com a questão da base empírica da teoria, a saber: a questão da amplitude e da extensão da pesquisa comparativa, únicos bastiões da validade dos princípios postos em evidência. Quão numerosos devem ser os comportamentos teatrais estudados para que as tendências evidenciadas possam ser consideradas realmente significativas, ou seja, não casuais e não explicáveis, por exemplo, tendo por base os contatos historicamente documentados ou apenas plausíveis?

E, sobretudo: com quais critérios deve ser conduzida a escolha dos comportamentos a comparar para que se possa produzir os resultados esperados e úteis? São questões que não encontram respostas satisfatórias nem em $A$ canoa de papel nem em outro lugar dentro do domínio da Antropologia Teatral e dos escritos de Barba.

Duas conclusões, em resumo, sobre a questão da Antropologia Teatral como ciência: uma sobre sua identidade problemática e outra sobre suas ambições teóricas.

Primeira conclusão: A Antropologia Teatral é, ou apenas pretende ser, ao mesmo tempo uma disciplina teórica e uma "ciência pragmática"; para dizer de outro modo, é uma ciência, é uma pedagogia, é uma estética.

Segunda conclusão: como abordagem analítico-teórica, ela se apoia numa concepção deliberadamente fraca, ou melhor, muito fraca, da ciência (Taviani: "Estudo empírico das comparações entre comportamentos teatrais"). 


\section{Referências}

BARBA, Eugenio. Le canoë de papier. Traité d'Anthropologie Théâtrale. Lectoure: Bouffonneries, n. 28-29, 1993. [A Canoa de Papel. SP: Hucitec,1994; Brasilia: Ed. Dulcina, 2009; The paper canoe. London: Routledge, 1995].

BROOK, Peter. Preface. In: Grotowski. Vers un théâtre pauvre. Lausanne: L'Age d'Homme, 1971. [Em busca de um Teatro Pobre. Rio de Janeiro: Editora Civilização Brasileira, 1971; Per un teatro povero, Roma: Bulzoni, 1970; Towards a Poor Theatre. London: Routledge, 1993].

DE MARINIS, Marco. Il teatro dell'altro. Interculturalismo e transculturalismo nella scena contemporanea. Firenze: La Casa Usher, 2011

GROTOWSKI, Jerzy. Tecniche originarie dell'attore. Roma: Università di Roma I "La Sapienza", 1982.

MARC, Yves. Etienne Decroux: maître du mouvement. In: PEZIN, Patrick (Ed.). Etienne Decroux, mime corporel. Saint-Jean-de-Védas: L'Entretemps Editions, 2003.

SCHINO, Mirella. Alchimisti della scena: teatri laboratori del Novecento europeo. Roma: Editori Laterza, 2009. [Os alquimistas da cena. São Paulo: Perspectiva, 2012; Alchemists of the Stage. Theatre Laboratories in Europe, Holstebro-MaltaWroclaw: Icarus Ed., 2009]

VACIS, Gabriele. Awareness. Dieci giorni con Grotowski. Milano: Rizzoli, 2002. 